\title{
HEREDO-FAMILIAL VASCULAR AND ARTICULAR CALCIFICATION
}

\author{
BY \\ J. SHARP \\ From the Rheumatism Research Centre, University of Manchester, \\ and the Royal Infirmary, Manchester
}

(RECEIVED FOR PUBLICATION JANUARY 4, 1954)

This report concerns a family, several members of which display an unusual type of calcification of joint structures and arteries, calcification and ossification of ligaments, and juxta-articular and periosteal new bone formation.

The full syndrome is a readily recognizable clinical entity and appears to be rare, since only two previous reports of similar cases have been traced in the literature. Magnus-Levy (1914) described a patient, a 47-year-old German female, who gave a history of recurrent attacks of painful joint swellings, starting in her teens in isolated fingers and later involving the hands and elbows. Each attack was followed by firm enlargement of the affected joints. She later developed intermittent claudication in the legs and evidence of heart failure. The joints of the fingers were enlarged, there was extensive thickening and tortuosity of the larger limb vessels, and radiologically there were calcifications in relation to the olecranon, patella, and finger joints, and the thickened vessels showed heavy calcification of an unusual pattern.

Levitin (1945) reported the case of a 24-year-old American serviceman who complained of painful swelling of the joints of the hands and pain in one knee of 2 weeks' duration. He also had painless swelling of the finger joints and nodular thickening of the arteries of the limbs and the tongue, but there was no obvious abnormality of the peripheral circulation. The radiological changes closely resembled those in Magnus-Levy's patient.

\section{Case Reports}

Case 1. A 47-year-old taxi-driver complained of attacks of painful swelling in the hands and feet, stiffness of the back, and pain in the calves on walking.

He gave a history that about 20 years ago he suddenly developed pain and swelling of the dorsum of the right hand with heat and redness of the overlying skin. Over the next few days the wrist and fingers became affected, the whole region being uniformly swollen. Moderate spontaneous pain was present, and movement of the wrist and fingers was excruciatingly painful. The attack gradually subsided in about 4 weeks, leaving slight residual enlargement of the wrist and finger joints. Some months later, an identical attack occurred in the left hand and similar milder attacks were noted subsequently in the feet and on one occasion in the right elbow. He had not felt ill, and did not think that he had been febrile during these episodes. The attacks, always confined to one site, occurred at irregular intervals of about 2 to 6 months, and each attack left further joint enlargement in the affected region with some limitation of movement. During the past 10 years or so, the attacks had been much milder, involving one or sometimes two or three adjacent fingers, and small transitory painful lesions had developed at new sites, particularly over such bony prominences as the ischial tuberosities and heels, and once over the manubriosternal region. In addition, he had noted occasional aching in the larger joints, particularly the knees and shoulders.

About 10 years ago, following forcible extension of the spine in a road accident, he was troubled for a few weeks by aching in the thoracic region of the back, and since then had noted progressive stiffening of the back and neck and had developed a slight stoop. Only in the past few months had he had any further back pain, this time at the base of the neck. Some 2 years ago, pain typical of intermittent claudication developed in the calves, both being affected at the same time. The pain was initially brought on by walking about half a mile, but the pain-free distance has gradually decreased to about 100 yards, the progression of symptoms on the two sides being exactly parallel.

Although he had gradually lost about 2 stones $(12.7 \mathrm{~kg}$.) in weight since the first symptoms, his general health had remained good and he had no other symptoms. His only past medical history was of an attack of left-sided ophthalmic herpes zoster 11 years previously.

His sister, he said, had suffered similar attacks of painful swelling in the hands with residual enlargement of the finger joints. He knew of no other family history of similar disease.

Examination.-He was a healthy-looking, sparelybuilt man, who stood with about $30^{\circ}$ total flexion deformity, due to a smooth, fixed lumbo-thoracic kyphos; 


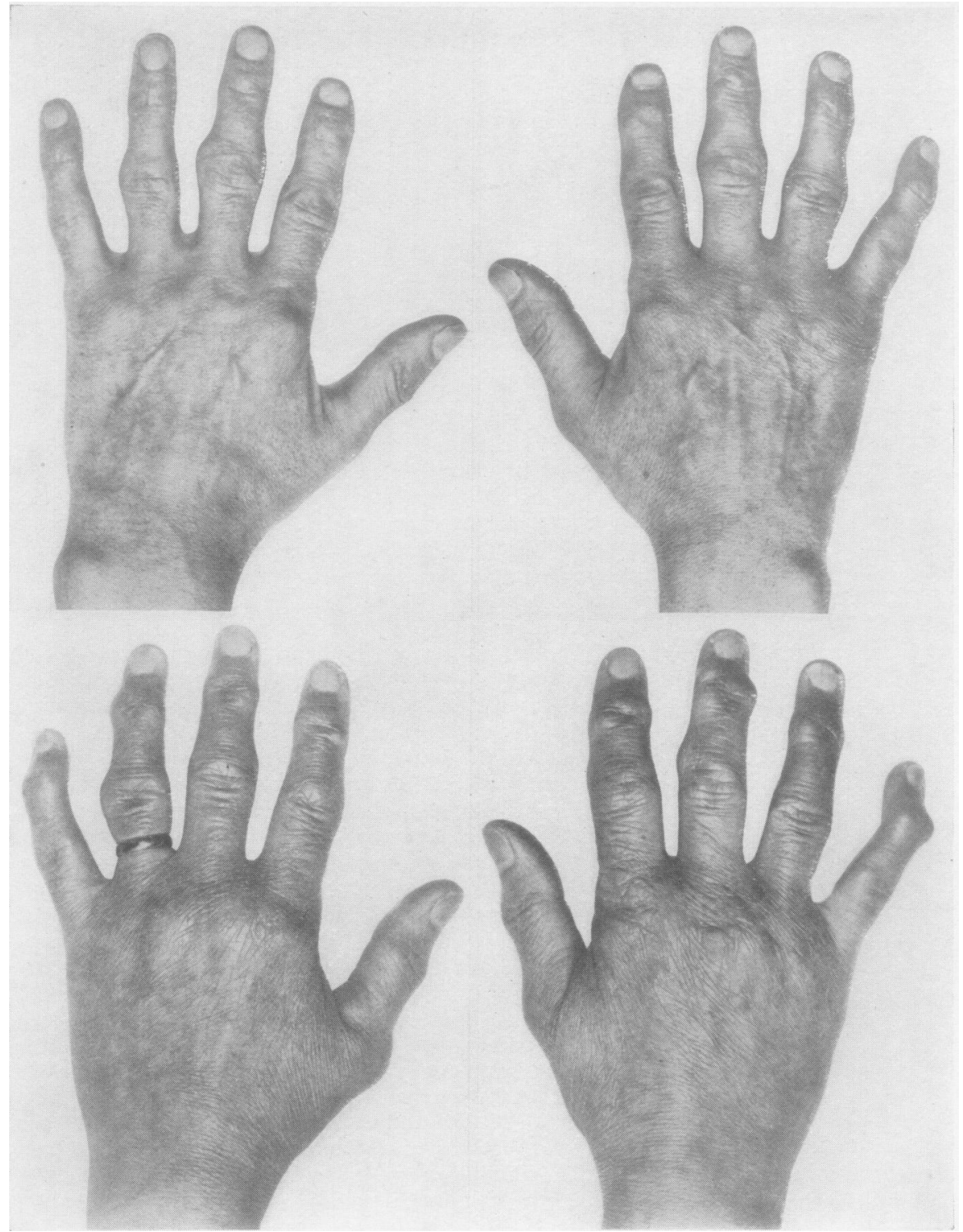

Fig. 1(a).-Case 1, show- के ing asymmetrical, largely $\Rightarrow$ bony enlargement of finger joints.

Fig. 1(b).-Case 2, showing more marked similar changes.

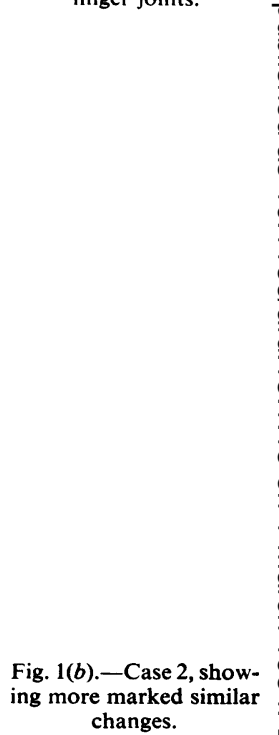

he had between a quarter and a half of the normal range of neck movement. Chest expansion was $3.5 \mathrm{~cm}$.

The texture, temperature, and sweating of the skin of the extremities was normal. The joints of the fingers (Fig. 1a) showed striking bony enlargement, and around the fifth metacarpo-phalangeal and fourth and fifth proximal interphalangeal joints of the right hand, which had been the site of a mild flare-up some weeks previously, there was also slightly tender soft tissue thickening; the remaining hand joints were not tender. There was moderate mechanical limitation of finger movement but hand function was good. The first carpo-metacarpal joints were not enlarged, but their motion was slightly limited and accompanied by crepitus. The wrists showed moderate restriction of movement and there was a slight flexion deformity of the elbows. The sternoclavicular and manubriosternal joints were slightly enlarged and tender, and the movement of both shoulder girdles was slightly restricted. The toes were normal apart from dorsal subluxation of the outer metatarso-phalangeal joints on the left. The tarsi showed a valgus deformity and slight limitation of movement. There was slight bony enlargement of ankles and knees with crepitus on motion of the latter. Hip movement was full and painless, and straightleg raising was to $90^{\circ}$ on each side. Both ischial tuberosities were slightly tender. 
Palpable nodular thickening of the radial, brachial, femoral, and left superficial temporal arteries was present; dorsalis pedis and posterior tibial pulses were absent on both sides, these vessels being impalpable. The retinal vessels appeared normal. Oscillometry showed greatly diminished pulsations in both calves and in the upper limbs the flush of reactive hyperaemia (Pickering, 1933) appeared at the tips of the digits of the left hand in 4 seconds, and at the tip of the right thumb in 5 seconds and of the right fingers in 7 seconds.

There was some pallor of the conjunctivae; no abnormality was noted in the viscera or lymph glands. Apart from anaesthesiae over herpes scars, in the left frontal region, no abnormality was detected in the nervous system.

Radiological Investigations.-The appearances were most unusual. The hands (Fig. 2a) showed enlargement and rather widely-spaced trabeculation of the ends of the metacarpals and phalanges with asymmetrical deposition of new bone, mainly at a short distance from the articular surface; the shafts of the phalanges appeared thickened probably because of the incorporation of periosteal new bone which was evident on several (particularly on both the fifth proximal) phalanges. This irregular new bone formation resulted in the false appearance of "erosions" of several metacarpal heads (notably the right fifth), and of the bases of both fifth proximal phalanges. The joint spaces proper were normal throughout, but in some of the terminal interphalangeal joints the growths of new bone had approximated at the joint margins, giving a

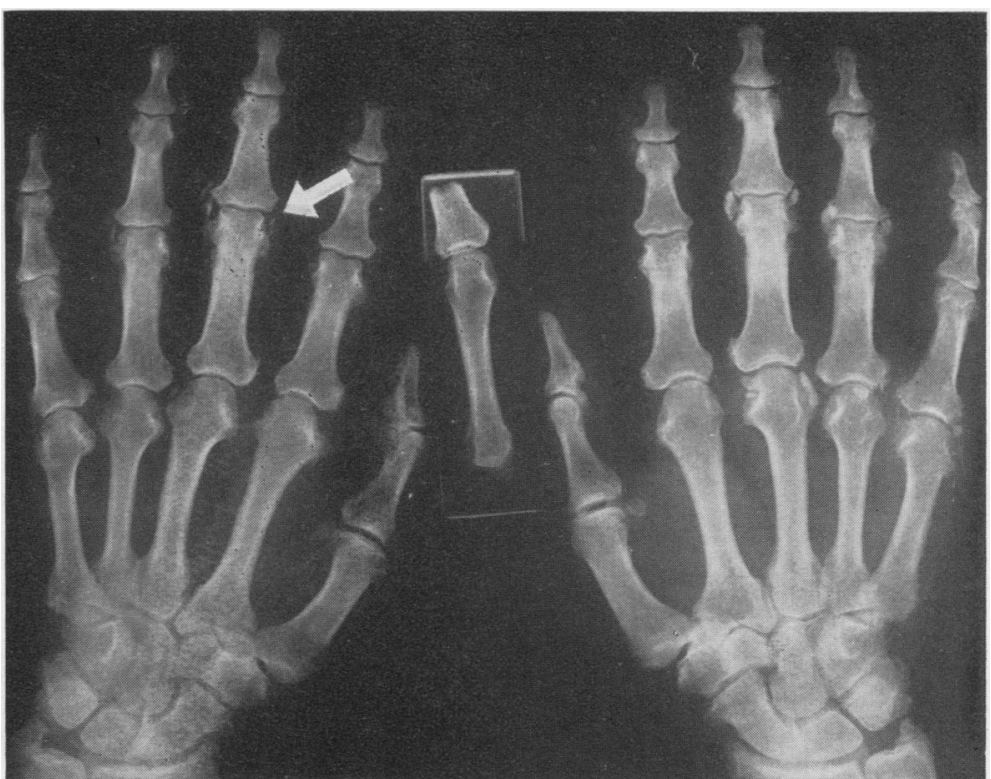

Fig. 2(a).-Case 1, radiographs showing enlargement of bone ends, periosteal new bone on thickened phalangeal shafts, and capsular and intra-articular calcification.

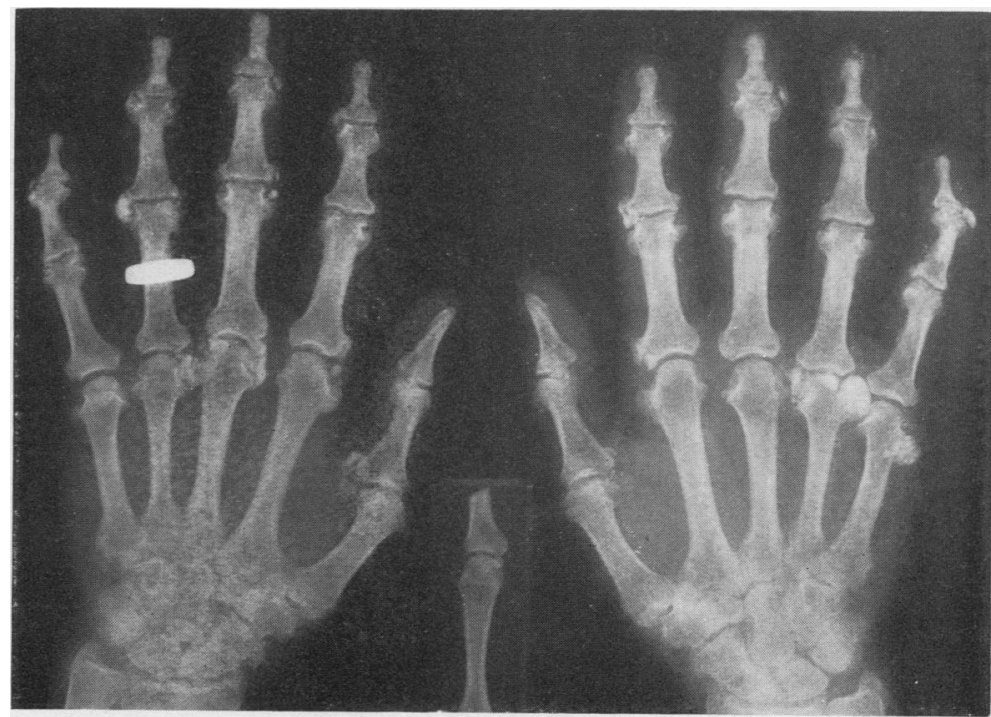

Fig. 2(b).-Case 2, radiographs showing more severe changes.

spurious appearance of narrowing. Amorphous depositions of calcium were present in close relation to almost all the finger joints. The appearance suggested that the calcification was in some cases intra-articular and in others in joint capsules (Fig. $3 a$, overleaf). Calcium deposits were present in relation to both first carpometacarpal joints, and there was deposition of irregular new bone on the lower ends of both ulnae. Radiographs (Fig. 5a, overleaf) confirmed the subluxation of the outer metatarso-phalangeal joints on the left, and suggested enlargement of the metatarsal heads and bases of the proximal phalanges. There was definite erosion of the heads of the left third, fourth, and fifth metatarsals, with probable narrowing of the fifth metatarso-phalangeal joint space. Calcification, of lesser degree but of the same type as the fingers, was visible in relation to several metatarso-phalangeal and interphalangeal joints, and faintly calcified vessels were visible in both first interosseous spaces. Irregular new bone was present on both medial cuneiform bones, and, in the lateral view, bony spurs were present on the plantar surface of each os calcis. Anterior and posterior tibial arteries on both sides 

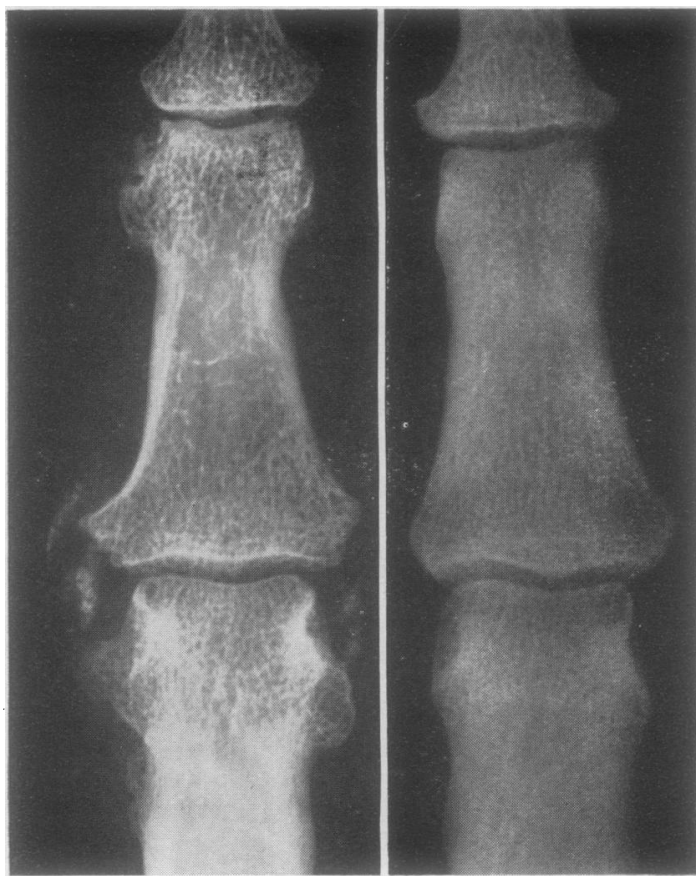

Fig. 3(a).-Case 1, enlargement of area indicated by arrow in Fig. 2(a), showing bony enlargement and articular calcification.

showed heavy clumpy calcification. New bone was present on both femoral condyles (Fig. 4a), and faint spotty calcification in relation to the lateral compartment of the right knee. The striking feature of the films depicting the knee joints was, however, the gross clumpy calcification of both popliteal arteries, and the fainter calcification of an unusually tortuous long saphenous vein on the left side. Radiographs of the calves showed that the calcification continued in the anterior and posterior tibial and peroneal arteries.

New bone formation was evident on the epicondyles of the left humerus, there were small soft tissue calcifications in relation to both elbow joints, and on each side the proximal portion of an interosseous artery was faintly calcified.

New bone was also present on the upper aspect of the right greater trochanter (Fig. 6a); the hip joints appeared normal. The pelvis was asymmetrical and was tilted backwards because of the kyphos, and both ilia appeared to be more vertical than normal, and to be thickened above the acetabulum. There appeared to be new bone formation over both ischial tuberosities, and, on the left, this partly surrounded a translucent area which may in part have resulted from bone erosion. The left sacro-iliac joint appeared fused, whereas on the right some joint space was retained, though the margins were sclerosed and irregular. A good joint space was visible at the symphysis pubis, where the appearances otherwise resembled those of the right sacro-iliac joint. Clumpy

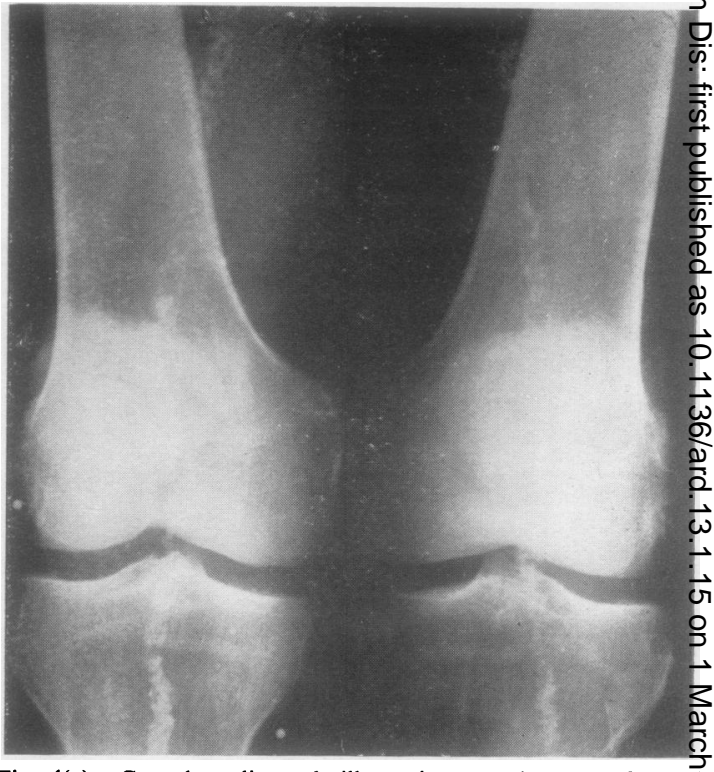

Fig. 4(a).-Case 1, radiograph illustrating new bone on femoral condyles, faint calcification in relation to lateral compartment do right knee, heavy calcification of popliteal arteries, and faint calc\} fication of left long saphenous vein. (Two lead pellets also present near right knee.)

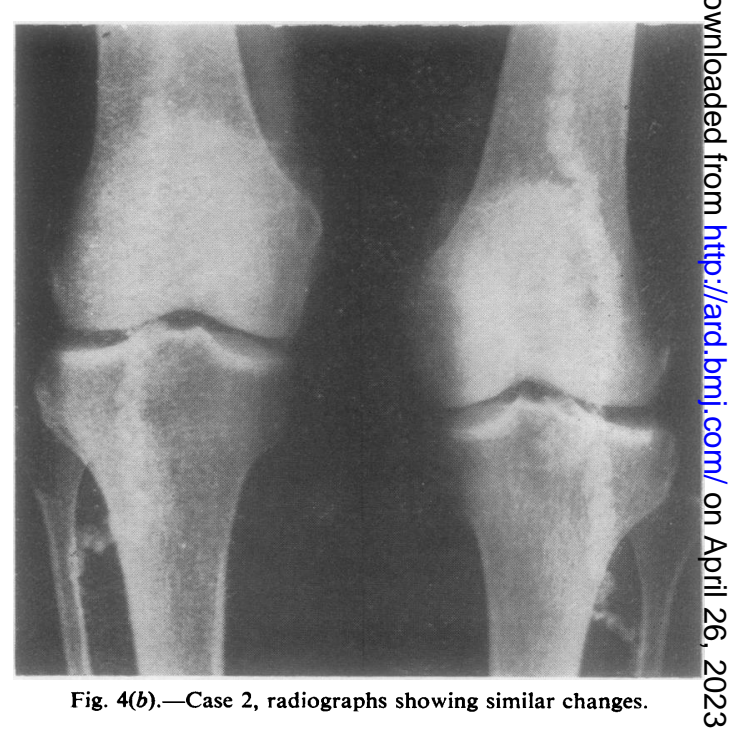

calcification was visible in vessels in the pelvis and uppe? thighs, probably the gluteal, femoral, and profundes femoris arteries and some of their branches; these vesselई appeared rather wider than normal.

The appearance of the lumbar spine on anteroposterior projection (Fig. 7) resembled the "bamboe" spine" of advanced ankylosing spondylitis, but, in the् lateral view (Fig. 8a), in spite of extensive ligamentou f $^{2}$ ossification, there was none of the characteristic squaring of the vertebral bodies, and the vertebral plates appeared 
to be duplicated. The anterior aspect of the lower abdominal aorta was faintly outlined by a fine streak of calcification. Multiple small calcifications were visible in the upper abdomen, probably in visceral vessels. There was wedging of the eighth thoracic body (Fig. 9a) and anterior osteophytosis of the adjacent bodies at the T8/9 space. The T9/10 space was fused anteriorly at, or just anterior to the disk margin. At the posterior ends of the disk spaces, there appeared to be bony continuity between most of the vertebral bodies. Calcification was visible in the disk substance of the $\mathrm{T} 6 / 7$ space and, in lesser degree, in the $\mathrm{T} 9 / 10$ and T10/11 disks.

In the cervical spine the upper disk spaces were normal, but the $\mathrm{C} 2 / 3$ space was almost sealed anteriorly by beak-shaped overgrowths of the corresponding bodies, resembling osteophytes. At the site corresponding to these growths on the anteroinferior margin of the fourth cervical body, a small, oval amorphous calcification was lying in contact with the vertebra. Apart from slight spondylosis at the C7/T1 level, the cervical spine appeared otherwise normal. Extensive clumpy calcification was visible in vessels, probábly medium-sized arteries, in the front of the lower neck.

The skull was normal. The pineal body was calcified. Multiple calcifications, probably within costal cartilages were seen on the radiograph of the chest but there was no definite calcification of the pulmonary vessels. There was erosion of several ribs, of the type seen in coarctation of the aorta.

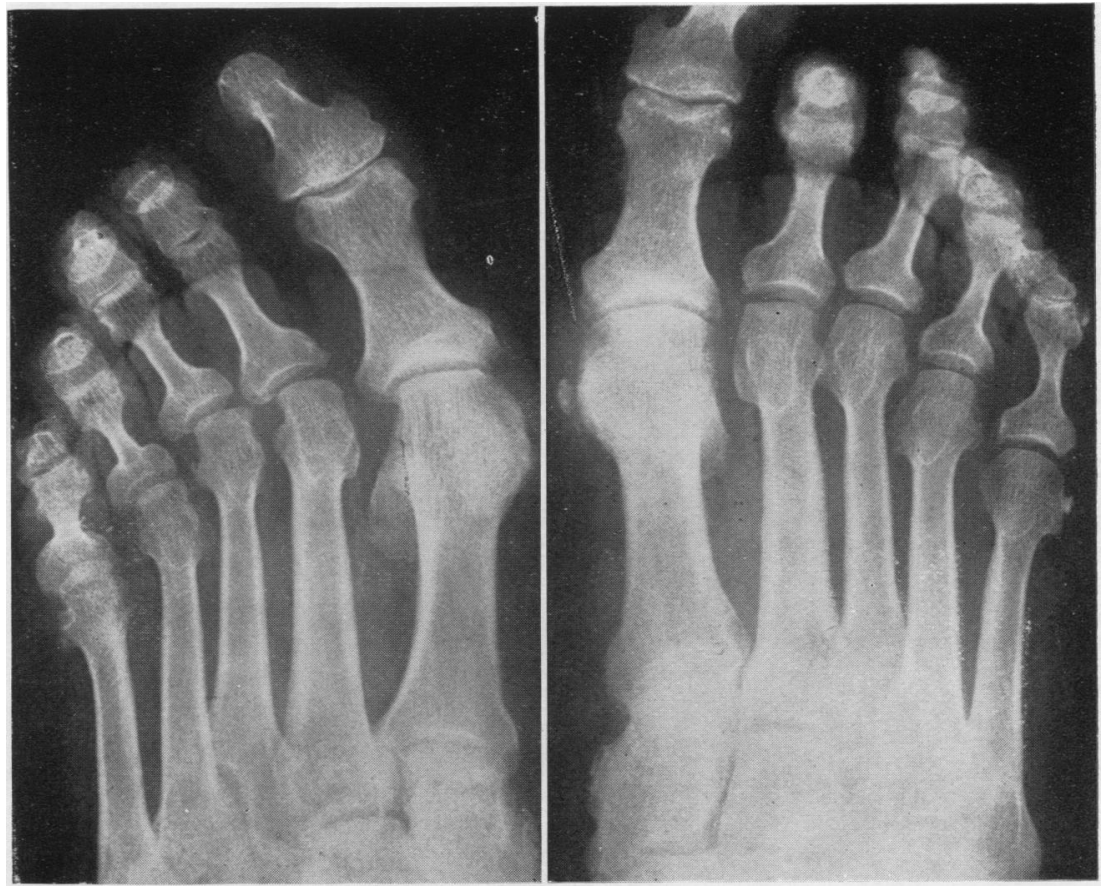

Fig. 5(a).-Case 1, radiograph showing subluxation of outer metatarso-phalangeal joints and erosion of outer metatarsal heads of left foot, small calcifications in relation to metatarso-phalangeal and interphalangeal joints, and faintly calcified first metatarsal arteries.
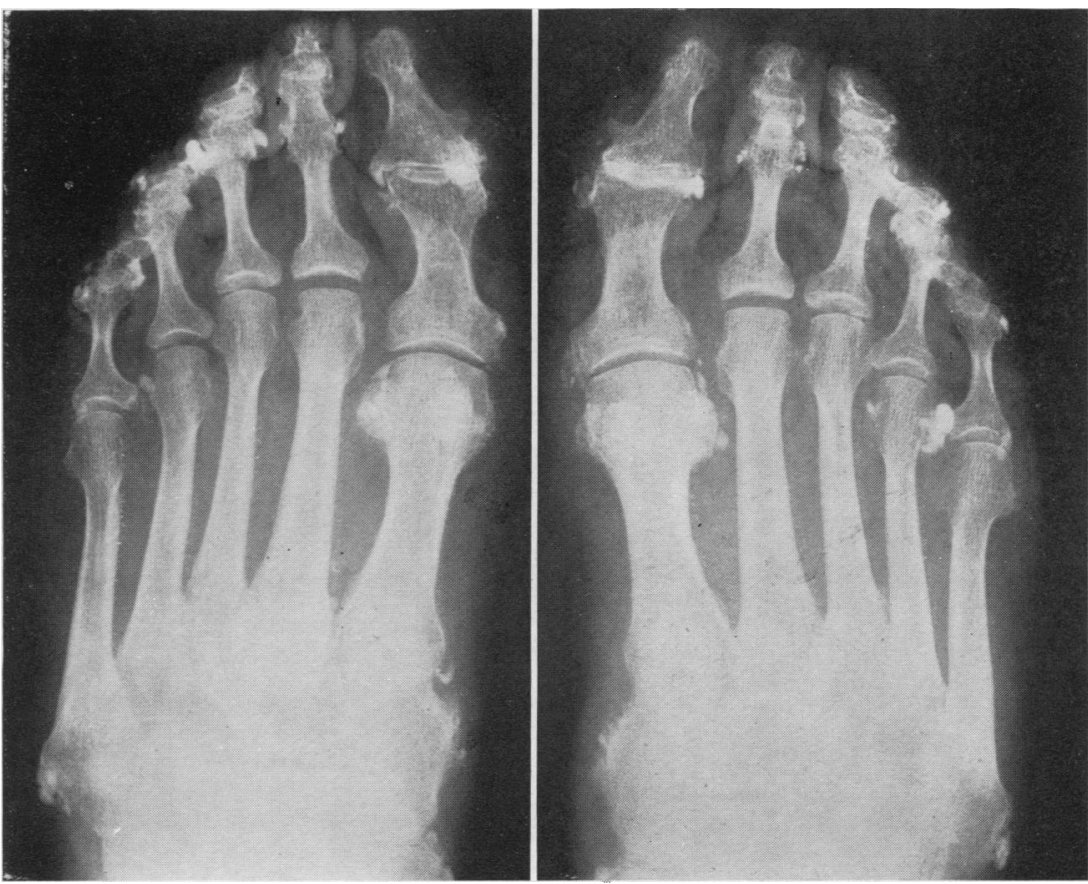

Fig. $5(b)$.-Case 2, showing slight porosis of outer metatarsal heads and extensive articular calcifications. 


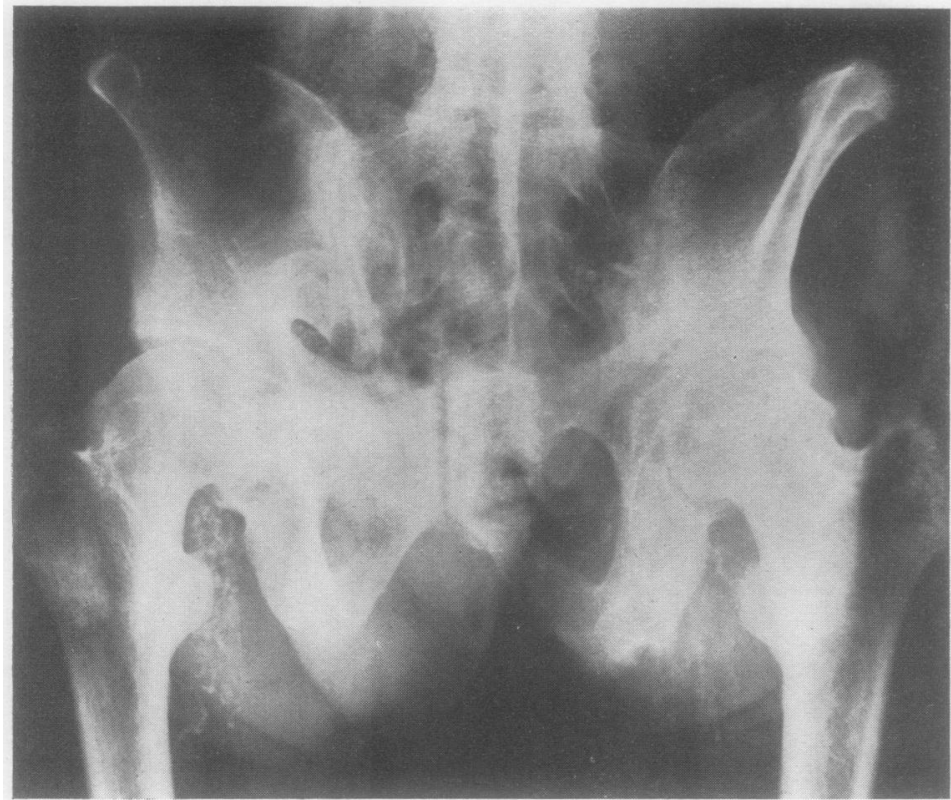

Fig. 6(a).-Case 1, radiograph showing asymmetry of pelvis, new bone formation on right greater trochanter and ischial tuberosities, fusion of left and narrowing of right sacro-iliac joint with sclerosis and irregularity of the margins of the latter and of the symphysis pubis. Heavy calcification is visible in gluteal, femoral, and profunda femoris arteries and some of their branches.

Fig. $6(b)$.-Case 2, radiograph of pelvis, showing similar but less marked asymmetry, periosteal new bone on greater trochanters and anterior superior iliac spines, and heavy calcification of iliac, femoral, and profunda femoris arteries.

Laboratory Investigations.

Haemoglobin 70 per cent. $(10 \cdot 4$ g. $/ 100 \mathrm{ml}$.).

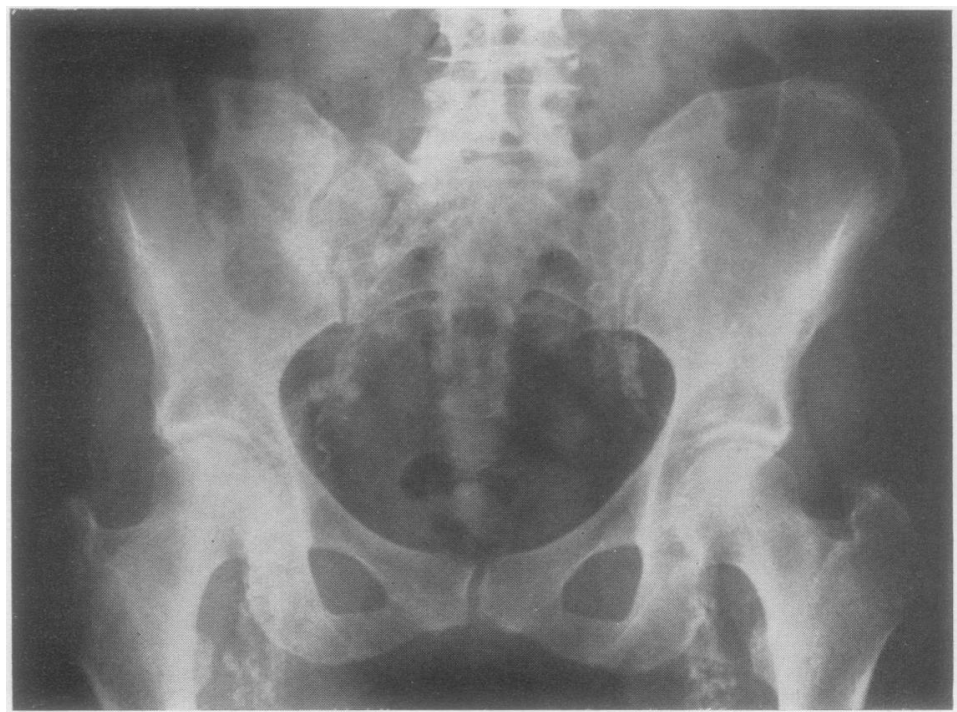

Haematocrit 35 vols. $/ 100 \mathrm{ml}$.

Mean corpuscular haemoglobin concentration 30 per cent.

White blood cells $8,600 / \mathrm{c} . \mathrm{mm}$.

Differential count normal.

Serum calcium $9.6 \mathrm{mg} . / 100 \mathrm{ml}$.; Serum phosphorus $3 \cdot 1$ mg./100 ml.; Serum alkaline phosphatase 17 units/100 $\mathrm{ml}$. (on two occasions); Serum uric acid $3.1 \mathrm{mg} . / 100$ ml.; Serum cholesterol $110 \mathrm{mg} . / 100 \mathrm{ml}$.; Serum bilirubin $0.5 \mathrm{mg} . / 100 \mathrm{ml}$.; Serum thymol turbidity 2.4 units.

Plasma cholesterol $597 \mathrm{mg} . / 100 \mathrm{ml}$.; Plasma alkali reserve 71 vols. $\mathrm{CO}_{2} / 100 \mathrm{ml}$.; Serum albumin $3.8 \mathrm{~g} . / 100 \mathrm{ml}$.; Serum globulin $2 \cdot 5 \mathrm{~g} . / 100 \mathrm{ml}$.

Serum protein electrophoresis: albumin normal, $\alpha_{1}$ globulin normal, $\alpha_{2}$ globulin moderately increased, $\beta$ globulin moderately increased, $\gamma$ globulin normal.

Urine: albumin free, neutral or acid, specific gravity 1,020, centrifuged deposit normal, culture sterile; Urea clearance 97 per cent. average normal; Plasma urea $30 \mathrm{mg} . / 100 \mathrm{ml}$.; Urine amino-acid nitrogen $382 \mathrm{mg} . / 24 \mathrm{hrs}$; Urine amino-acid paper chromatography, normal pattern; Urinary calcium excretion $191 \mathrm{mg} . / 24 \mathrm{hrs}$ (on ward diet giving an approximate daily intake of $1,200 \mathrm{mg}$. calcium).

Blood Wassermann reaction negative. 


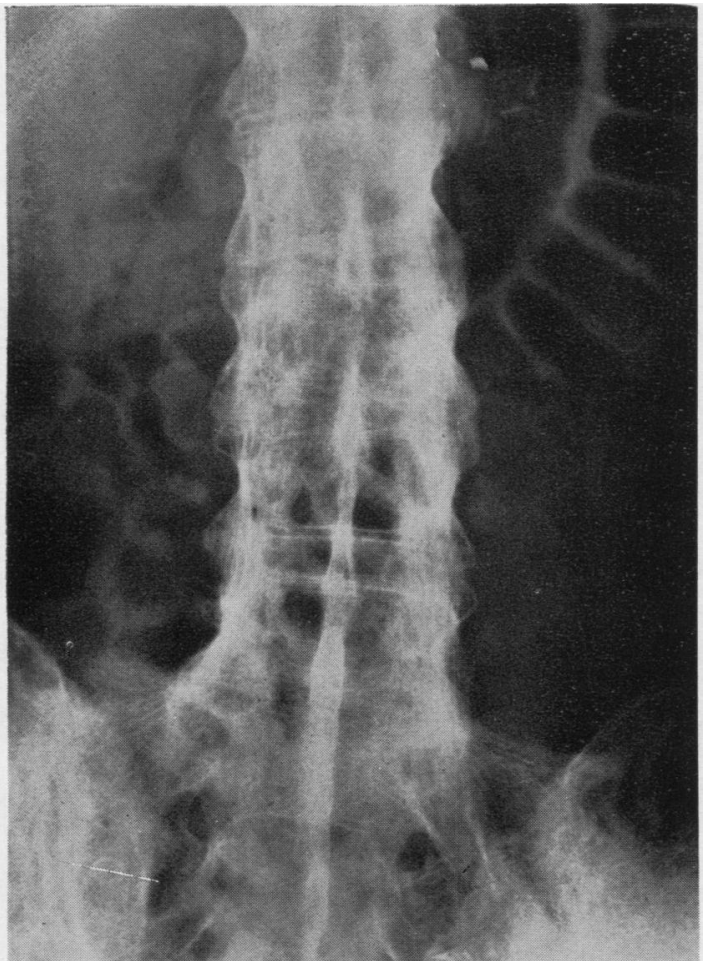

of the affected finger joints with a little limitation of movement. She thought that a course of gold injections given about 13 years ago was of benefit, and during the past 10 years or so the attacks had been much milder and confined to isolated finger joints.

Some 10 years ago she also developed typical intermittent claudication simultaneously in both calves on brisk walking. Shortly after this, she began to lose weight, became pale and breathless, and noted an increase of a chronic, slightly productive cough to which she had been subject for a number of years. Eventually, 7 years ago, pernicious anaemia was diagnosed, liver injections were given with apparent benefit, and she regained her normal weight. In spite of the improvement in the anaemia, the claudication persisted, and the distance she could walk briskly without pain had gradually decreased to about 200 yards.

Her first symptoms in the feet were noted 2 years ago; these consisted of aching across the dorsum of the forefoot on walking and attacks of burning discomfort in the soles in bed. The latter attacks were particularly severe in winter; they were eased by movement of the feet and relieved by walking about.

She had never had any trouble with the back, and had noted no other symptoms other than occasional hot flushes since the menopause 3 years ago. In her past history she recalled "growing pains" in the lower limbs, which ceased at about 10 years of age, but no serious illnesses.

Fig. 7.-Case 1, radiograph of ankylosed lumbar spine with extensive ligamentous ossification.

Electrocardiogram normal.

Blood sedimentation rate varied between $30 / 200 \mathrm{~mm}$. and $16 / 200 \mathrm{~mm}$. (Westergren) during 6 weeks' observation.

Rose's serum differential agglutination test (modified Ball, 1950) at weekly intervals, gave negative results on the first two occasions and positive results on four occasions thereafter.

Arteriography via right brachial artery showed all digital arteries patent.

Case 2. Sister of Case 1, a housewife, aged 50 years, stated that at the age of 19 she had pain in the manubriosternal region for about one month, particularly on cough ing or sneezing. Her next symptom occurred 20 years ago, when she developed a painful swelling involving the whole right upper limb, and the swelling subsided in about 3 weeks. During this attack she was not ill, and she was disturbed only by the pain. An identical attack occurred in the left hand 2 weeks later, and subsequently she had similar attacks in the hands at intervals of one to two years, both hands being sometimes affected simultaneously. These attacks sometimes involved the fingers, and after each attack she noted some enlargement

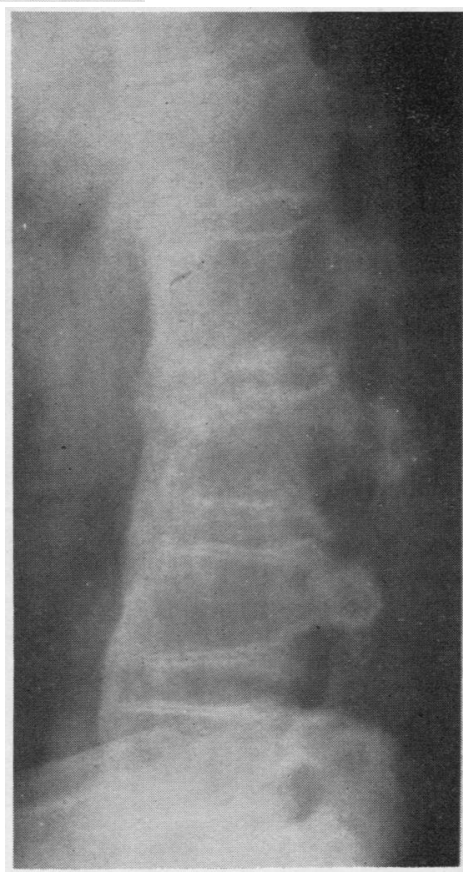

Fig. 8(a).-Case 1, lateral radiograph of lumbar spine, illustrating duplicated vertebral plates and lack of squaring of vertebral bodies.

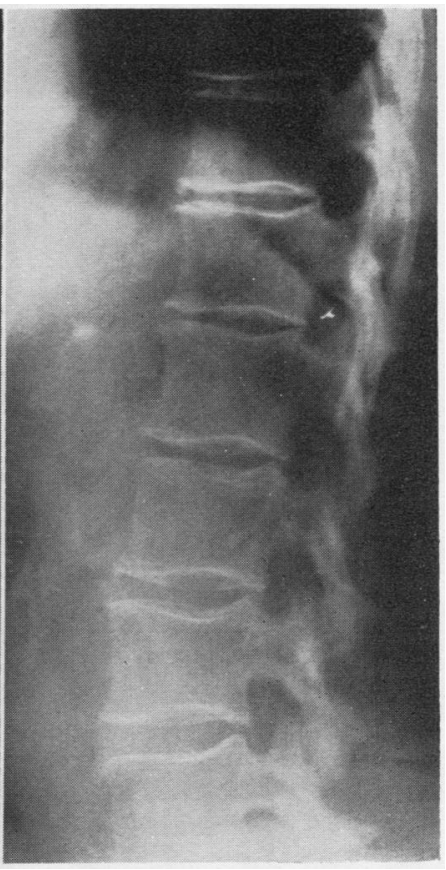

Fig. 8(b).-Case 2, similar view, showing only slight porosis and minor osteophytosis of vertebral bodies. 


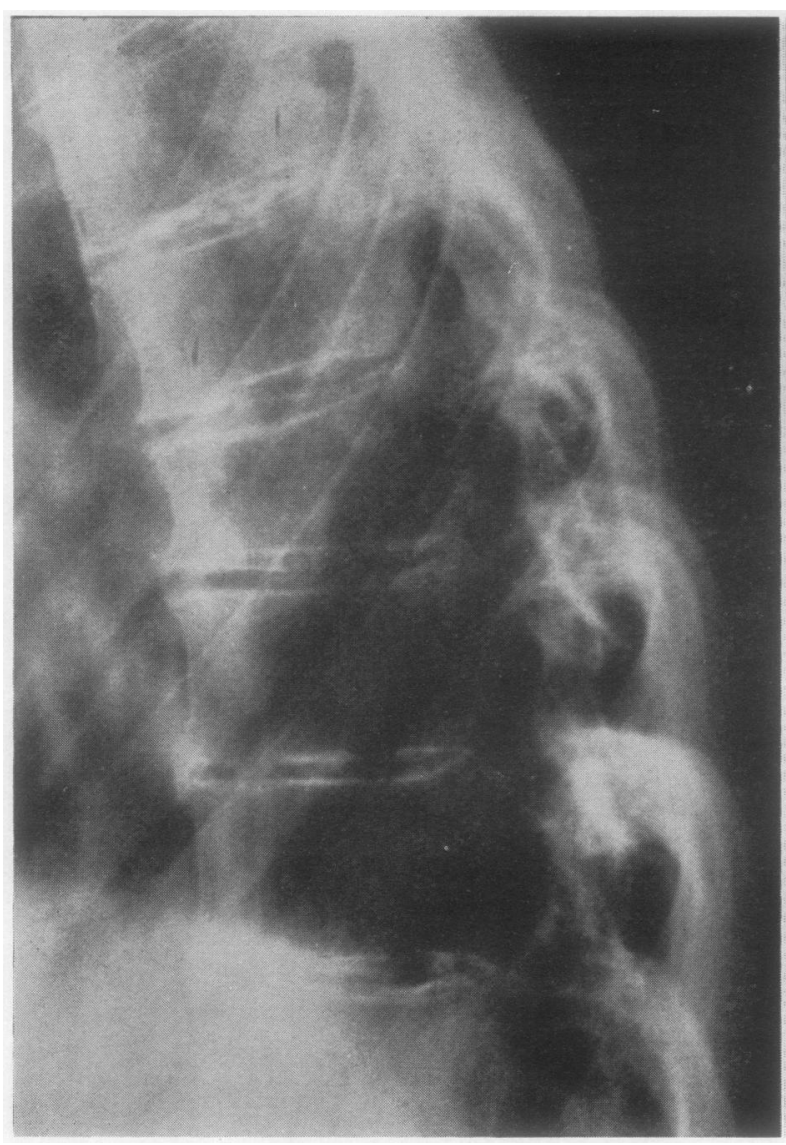

Fig. $9(a)$.-Case 1, lateral radiograph of thoracic spine, showing wedging of 8 th thoracic body, bony continuity between several vertebral bodies posteriorly, anterior osteophytosis at $T 8 / 9$ and fusion at $\mathrm{T} 9 / 10$ spaces, and calcification in substance of disks $\mathrm{T} 6 / 7$, $9 / 10$ and $10 / 11$.

Examination.-She was a pale, well-nourished woman, bearing some facial resemblance to her brother, Case 1 . Her hands (Fig. 1b), which were of normal temperature, colour, and moisture, were strikingly similar to his, with even more marked non-tender enlargement of the finger joints, the asymmetrical bony excrescences in some cases extending beyond the joint limits; there was flexion deformity of the terminal interphalangeal joints of both fifth fingers, and moderate limitation, apparently mechanical, of the others. The metacarpo-phalangeal joints showed rather less bony enlargement than the interphalangeal joints, and there was slight rubbery soft tissue thickening of both. Slight bony enlargement of both first carpo-metacarpal joints was present, with some crepitus on movement. The lower ends of the right radius and ulna and of the left ulna to a lesser extent were enlarged, and there was slight limitation of wrist movement. The external condyle of the right humerus felt slightly enlarged; both elbows lacked $5-10^{\circ}$ extension. Both shoulder girdles were considerably limited in movement, scapulo-humeral movement being full. In the

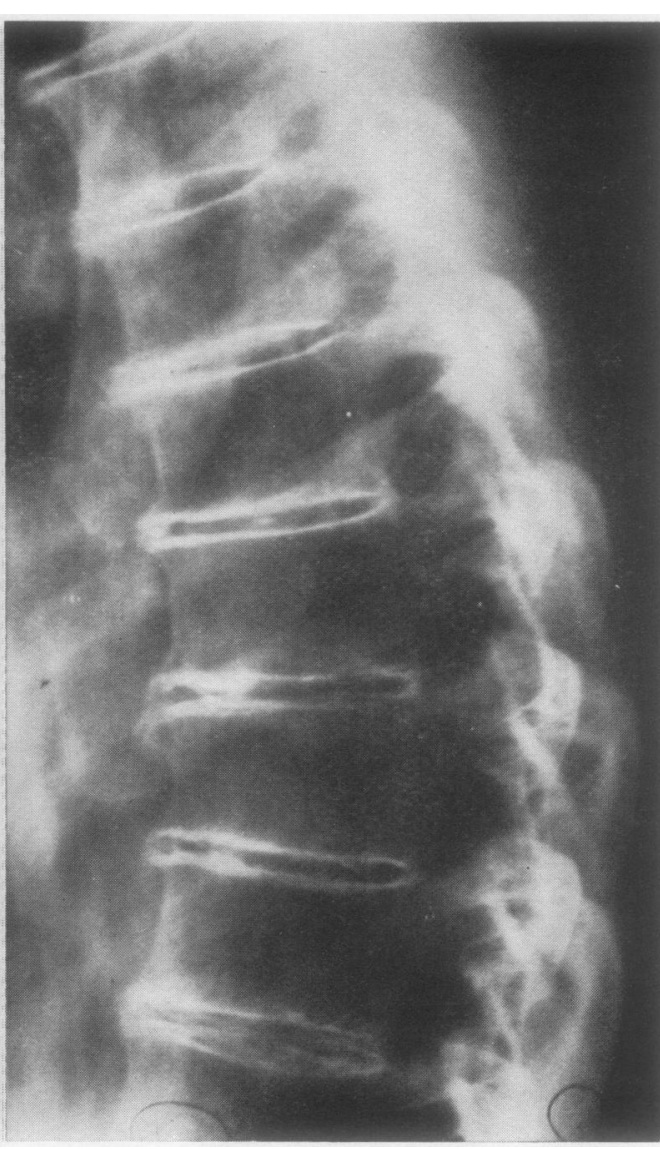

Fig. $9(b)$.-Case 2, radiograph of thoracic spine, showing calcification at disk margins and a small deposit in the substance of disk T8/9.

feet there was a little slightly tender soft tissue thickening of the outer metatarso-phalangeal joints and additionab slight bony enlargement of both first metatarso-phalangea 3 joints. The bases of the first and fifth metalarsals on each side were enlarged. The tarsi were normal, but there was slight limitation of movement at the right ankle. The right Achilles tendon was a little thickened and tender, ans. there were palpable bony spurs on each os calcis laterat to the insertions of the Achilles tendons. The bones around both knee joints felt rather prominent and were generally tender, and there was palpable irregularity of the upper outer aspects of both patellae. Terminal knee flexion was slightly painful on both sides. Hip movement was full and painless.

The lumbar spine was somewhat straightened and there was a slight thoracic kyphos. In the thoracic and ${ }^{+}$ lumbar regions, the range of movement was between quarter and a third of normal, and in the cervical region rotation was about a quarter of normal, movements in other directions being much less restricted. Chest expan $\bar{\Omega}$ sion was $6 \cdot 25 \mathrm{~cm}$. 
The brachial pulse was absent in the left antecubital fossa, and a finely nodular cord was palpable at the usual site of the artery. Both radial pulses were of poor volume, and the femoral and ankle pulses were absent, but these vessels were not palpably thickened. Other pulses and vessels appeared normal. Oscillometry revealed greatly diminished pulsations in both thighs, and the flush of reactive hyperaemia was delayed in all the fingers and in the left thumb.

There was slight conjunctival pallor and a little cyanosis of the lips and nail beds. There was no atrophy of the skin or significant lymphadenopathy. The heart was clinically slightly enlarged to the left, and a soft apical systolic bruit was heard. There was neither venous engorgement nor oedema, and the lungs and abdomen showed no significant abnormality. The feet were pink and the toes warm and rather dry. Cutaneous sensation was impaired over the right forefoot and in the tips of the toes on the left, and vibration sense was also slightly impaired over the right great toe. Slight wasting of the muscles of the right thigh was present without notable weakness. No other abnormality of the nervous system was detected.

Radiographs of the hands (Fig. 2b) showed changes identical with those in Case 1 , but more severe. The feet (Fig. $5 b$ ) showed similar but more extensive periarticular calcifications and slight porosis of the outer metatarsal heads. No calcification was visible in the metatarsal vessels. The knees (Fig. 4b) showed a little soft tissue calcification in the region of the femoral capsular attachments and severe arterial calcification, which continued in similar degree in the left anterior tibial artery as far as the ankle and in other calf vessels to a lesser extent. Faint calcification was visible in a tortuous right saphenous vein.

There was a little fluffy new bone on the outer aspects of both greater trochanters and anterior superior iliac spines (Fig. 6b), but the sacro-iliac and hip joints appeared normal. The pelvis showed a lesser degree of asymmetry of the type seen in Case 1. Heavy clumpy calcification was visible in the iliac, femoral, and profunda femoris arteries, which appeared widened, and in some of their larger branches.

The lumbar spine (Fig. 8b) appeared somewhat porotic with large disk impressions and small osteophytes on several vertebral bodies, but there was none of the bridging and gross ligamentous ossification seen in Case 1. The abdominal aorta was not calcified, but clumpy calcification was visible in two vessels in the upper abdomen, probably the left renal and gastro-duodenal arteries.

Calcified deposits were visible at the margins of most of the disk spaces in the thoracic region of the spine (Figs $9 b$ and 10); in some situations these lay internal to osteophytes, and several of the deposits appeared to be unconnected with vertebral bodies. The appearances suggested that the deposits had occurred in the outer layers of the annulus fibrosus and there appeared to be a small deposit also in the substance of the T8/9 disk. The heavy calcifications lateral to the spine in Fig. 10 were in costal cartilages and no abnormal calcification

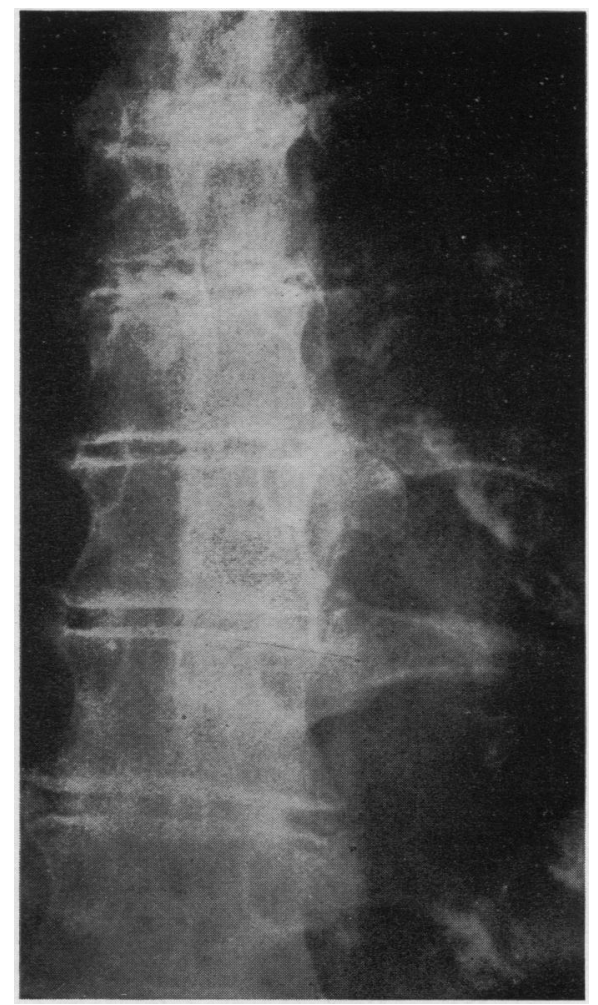

Fig. 10.-Case 2, radiograph of thoracic spine, showing marginal disk calcifications. In the lowest space these are unconnected with vertebral bodies. The heavy calcifications lateral to the spine are in costal cartilages.

was visible in the lung fields. Faint spotty and linear calcifications were visible in the arch and upper part of the descending thoracic aorta.

In the neck, the hyoid bone, and thyroid and cricoid cartilages, and the anterior aspect of the lower trachea were calcified. The lower disk spaces were slightly narrowed, with spotty calcification, and there was osteophytosis of the lower vertebral bodies. Spotty calcification was also present in several vessels, probably arteries, in the front of the neck.

Radiographs taken 16 months previously showed that several of the calcifications about the finger joints had increased appreciably in size while others had decreased; there had been no definite change in the radiographic appearances of the feet or pelvic vessels.

\section{Laboratory Investigations.}

Blood sedimentation rate $12 / 200 \mathrm{~mm}$. (Westergren); Haemoglobin 84 per cent. (12.4 g./100 ml.); Haematocrit 43 per cent.: Mean corpuscular haemoglobin concentration 29 per cent.; White cell count 4,700 / c.mm.; Differential count normal.

Serum calcium $10 \cdot 1 \mathrm{mg}$./ $100 \mathrm{ml}$.; Serum phosphorus $3 \cdot 3$ $\mathrm{mg} . / 100 \mathrm{ml}$.; Serum alkaline phosphatase 12 units/100 ml.; Serum uric acid $1 \cdot 2 \mathrm{mg}$. $/ 100 \mathrm{ml}$.; Serum cholesterol $210 \mathrm{mg} . / 100 \mathrm{ml}$.

Urine normal. 
Other Members of the Same Family

As this was clearly a familial syndrome, the family history of these patients was investigated in some detail. The parents of Cases 1 and 2, who were first cousins (Fig. 11), had both died from cerebro-vascular accidents. The father was known to be hypertensive in his later years, and his only sister died from a stroke<smiles></smiles>
83 brachial and radial arteries were observed; the other 3 limb vessels appeared normal. Moderate limitation of spinal movement and mild osteo-arthritic change in the peripheral joints were present. Radiographs of the hands, $\Rightarrow$ right forearm, feet, pelvis, lumbar and cervical spine, and $\stackrel{\text { क }}{\circ}$ chest showed evidence of disk degeneration and osteo-들

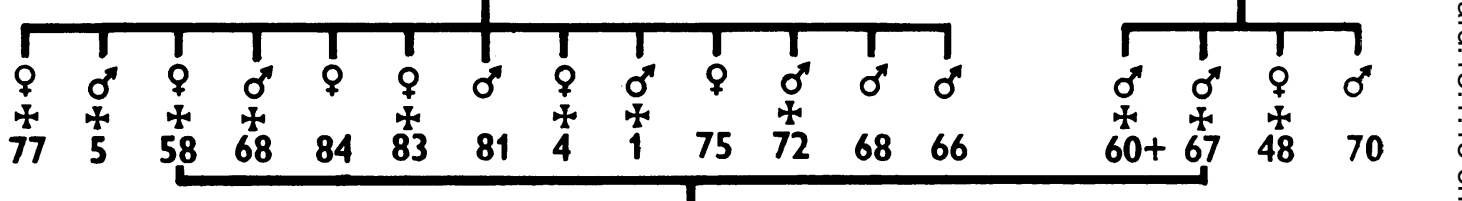

at the age of 48 years. None of the earlier generation appeared to have had any changes in the joints similar to those of Cases 1 and 2.

We were able to examine clinically and radiologically nine other members of the family, apart from Cases 1 and 2. These are included in (1) CASE NUMBER $1 A G E$ $+D E A D$ the dotted area of Fig. 11. Some manifestations of the familial disease were found in two brothers of the original patients, and in two children of Case 2. Brief records of these four cases are given below.

Case 3, the elder brother, aged 54 years, had always enjoyed good health.

Examination.-The only abnormalities noted were slight tortuosity and doubtful thickening of the right brachial, radial, and both posterior tibial arteries and mild hypertension. Radiographs disclosed no significant abnormality in the hands, feet, pelvis, or lumbar and cervical regions of the spine. Spotty calcification, much less dense than in Cases 1 and 2 was visible in the popliteal, posterior tibial, and proximal portions of the peroneal arteries on each side, and in the left first metatarsal artery.

Case 4, the eldest brother, aged 60 years, gave a history of recurrent attacks of low back pain since the age of 40 years and of angina of effort in the past 2 years.

Examination.-Severe hypertension and striking tortuosity and thickening of the right superficial temporal and right brachial and, to a lesser extent, of the left

arthritis in the spine, and early osteo-arthritic change in the joints of the hands and feet. The heart was considerably enlarged. Faint spotty calcification was visible in the first and second metatarsal and right ulnar arteries.

Case 6, son of Case 2, now aged 27 years, gave a $\delta$ a history of symmetrical claudication in the calves on rapid walking since the age of 16 years. No abnormality was noted on physical examination. Oscillometry $D$ revealed diminished pulsations in the left calf. The radiographic appearances of the hands, feet, and cervical spine were normal. The pelvis showed the same type of $\mathcal{O}$ asymmetry as Cases 1 and 2, and there was a slight $N$ compensatory lumbar scoliosis. Faint calcification was $N$ visible in both short saphenous veins; these were not $\omega$ tortuous or varicose.

Case 6, son of Case 2, now aged 27 years, gave a suggestive but not definite history of intermittent claudi- $\stackrel{\mathcal{P}}{?}$ cation in the calves on severe effort, also starting at the age of 16 years. No abnormality was noted on physical examination, or in the radiographs of the hands, feet, $\vec{D}$ calves, pelvis, or lumbar and cervical spine. Oscillometry $\frac{?}{\mathbb{Q}}$ of the calves gave normal readings. 
The five other members of the family who were examined were symptom free and appeared normal on examination. All were normotensive and showed negative results in the serum differential agglutination test. None had calcification of joint structures or of blood vessels in the hands, feet, pelvis, lumbar or cervical spine, or calves, but both the daughters of Case 1 and the daughter of Case 4 showed pelvic asymmetry of the type seen in Cases 1 and 2 .

Mode of Inheritance.-The most probable mode of inheritance is by a rare recessive gene, Cases 1 and 2 being homozygous and presenting the full syndrome, and Cases 3-6 being heterozygous and developing the syndrome in an incomplete form. On this hypothesis, the children of Case 1 should also be heterozygous and should develop the incomplete syndrome in due course, and some of the children of Cases 3 and 4 may also be heterozygous. The occurrence of the pelvic asymmetry in children who are otherwise at present unaffected may be significant in this respect.

It is possible that forebears other than the parents of Cases 1 to 4 may also have been heterozygous and that the incomplete syndrome may sometimes cause little if any disability and be compatible with longevity.

\section{Discussion}

The main features of these six cases and of the two previously reported are summarized in the Table. The full syndrome affecting joints, juxtaarticular bone, periosteum, and blood vessels as manifested in Cases 1 and 2 is a distinctive clinical picture. The history is usually characteristic, and the irregular, apparently largely bony, enlargement of joints, particularly of the fingers, and the nodular thickening of the peripheral arteries are striking. Radiologically, the changes in the joints and larger arteries are unmistakable. The spinal appearances in Case 1 in some views suggest ankylosing spondylitis, but it is quite exceptional to see such a degree of spinal change in ankylosing spondylitis without complete fusion of the sacro-iliac joints and squaring of lumbar vertebral bodies; the appearance of duplication of the lumbar vertebral plates is most unusual. Furthermore, the appearances in the thoracic spine of Case 2, which might reasonably be supposed to represent an earlier stage of this change, bear no resemblance to those of ankylosing spondy-

TABLE

SIX CASES COMPARED WITH THOSE PREVIOUSLY REPORTED.

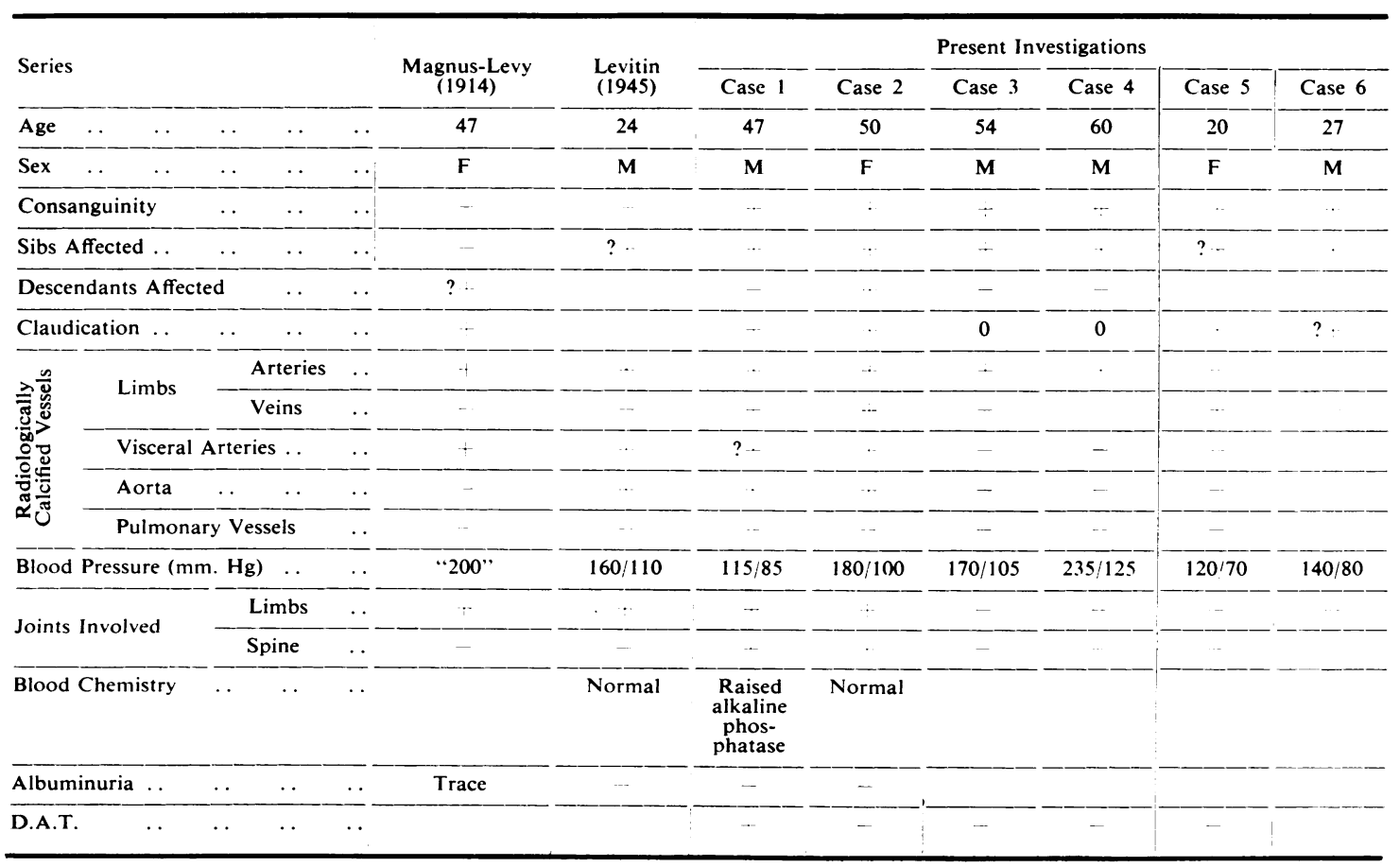


litis, and the sacro-iliac joints are radiologically normal.

The change in severely affected arteries, as might be expected from the radiological appearances, appears to be of a distinctive type. Levitin (1945), who biopsied a posterior tibial artery in his patient, found the media and intima fibrosed and grossly distorted with bizarre calcified patches containing deeply acidophilic hyaline bodies or granules usually embedded in the calcified plaques which projected into a considerably natrowed lumen. Occasional smaller deposits were also present in the adventitia. This patient was the only one of the four showing the full syndrome who was without intermittent claudication, in spite of heavy calcification of all the main arteries of his lower limbs.

Calcification of the arteries and around the joints but sparing the viscera, the common site of metastatic calcification, has been described in association with advanced renal failure (Albright and others, 1937; Hubbard and Wentworth, 1921), but both these cases showed evidence of hyperparathyroidism and grossly abnormal biochemical findings in the blood, and neither showed any overgrowth of bone. None of the three patients with this syndrome so investigated showed evidence of metabolic disturbances of this kind, which implies that the calcification is of the dystrophic variety, that is, secondary to a primary disturbance in the tissues.

The syndrome can be distinguished both by its natural history and by the anatomical location of the deposits from the other well-recognized forms of dystrophic calcification divided by Steinitz (1931), on clinical grounds, into the two categories of calcinosis universalis and calcinosis circumscripta. The former occurs most frequently in children, and extensive calcium deposition is found in the skin, subcutaneous tissues, muscles, fasciae, and tendons, usually associated with the development of joint contractures and ulceration of the superficial deposits. Its prognosis is grave, the patient usually succumbing to intercurrent infection after a prolonged enfeebling illness (Brooks, 1934), although remission and recovery do occasionally occur (Weber, 1914; Kennedy, 1932; Craig and Lyall, 1931). In calcinosis circumscripta, mainly a disease of adult women, deposits occur most commonly in the skin and subcutaneous tissues of the upper limbs, especially of the fingers, but without particular relation to joints; it is commonly associated with reduced circulation in the extremities and sclerotic changes in the fingers.

Localized calcifications of tendino-capsular structures around joints, particularly the shoulder joint, are occasionally encountered; similar deposits have been noted less frequently at other sites, such as the wrist and finger joints, and sometimes at several $\frac{}{\omega}$. sites in the same patient (Maseritz, 1935; Sutro and ? Cohen, 1941; Cooper, 1942; Vasko, 1946; Seidenstein, 1950). Hamilton (1951) suggested the descrip-o tive title calcinosis localisata for this condition; 들 the deposits may be asymptomatic, but are often $\frac{\bar{\sigma}}{2}$ revealed in radiographs taken to investigate acute $\mathbb{\otimes}$ painful swelling of the affected parts, the radiographic appearances resembling a minor form of the ${ }^{\text {s }}$ joint changes seen in the patients described above. $\vec{\circ}$ In calcinosis localisata, however, the deposits $\overrightarrow{\vec{\omega}}$ frequently disappear after these acute episodes; $\stackrel{\omega}{\mathscr{O}}$ this disease seems to have no familial incidence nor does vascular calcification occur in association with it.

\section{Conclusion}

The familial syndrome of calcinosis of the jointso and arteries here described is remarkable in that the calcinosis is associated with periosteal bone pro-z liferation and ossification of ligaments. It is therefore $\frac{\stackrel{m}{\sigma}}{3}$ best regarded as a distinct entity until the mechanisms $\stackrel{\text { }}{\stackrel{5}{ }}$ of dystrophic calcification are more fully understood. $\overrightarrow{0}$

Dystrophic calcification is probably due to a specific change in connective tissues, but it is not clear which connective tissue elements are concerned, and the nature of the disturbance is unknown. Future studies on the tissues of these patients may help to elucidate the problems of the site and $\overline{0}$ mechanism of abnormal calcification and ossification $\stackrel{2}{\Rightarrow}$ in connective tissue.

\section{Summary}

In a family resulting from the marriage of first cousins, two of the four siblings display calcification of joint structures and arteries of an unusual type $e_{-}^{\circ}$ together with juxta-articular and periosteal new bone 3 formation.

The son and daughter of one of these and the 3 remaining two siblings appear to have a milder form of the syndrome affecting the blood vessels only.

The disease appears to be a rare and distinct heredo-familial form of dystrophic calcification.

I am greatly indebted to Professor J. H. Kellgren forn much helpful advice, to Dr. H. Harris for assistance in the interpretation of the genetics of the syndrome, and to Dr. Robert Ollerenshaw and the staff of the Departmento of Medical Illustration for reproduction of the figures.

\section{REFERENCES}

Albright, F., Drake, T. G., and Sulkowitch, H. W. (1937). Bull.T Johns Hopk. Hosp., 60, 377.

Ball, J. (1950). Lancet, 2, 520.

Brooks, W. D. W. (1934). Quart. J. Med., n.s. 3, 293.

Cooper, W. (1942). J. Bone Jt Surg., 24, 114.

Craig J., and Lyall, A. (1931). Brit. J. Child. Dis., 28, 29.

Hamilton, A. R. (1951). J. Bone Jt Surg., 33B, 572. 
Hubbard, R. S., and Wentworth, J. A. (1921). Proc. Soc. exp. Biol. (N.Y.), 18, 307.

Kennedy, R. L. J. (1932). J. Pediat., 1, 667.

Levitin, J. (1945). Radiology, 44, 489.

Magnus-Levy, A. (1914). Dtsch. med. Wschr., 40, 1305.

Maseritz, I. H. (1935). J. Bone Jt Surg., 17, 1017.

Pickering, G. W. (1933). Brit. med. J., 2, 1106.

Seidenstein, H. (1950). J. Bone Jt Surg., 32A, 413.

Steinitz, H. (1931). Klin. Wschr., 10, 1132.

Sutro, C. J., and Cohen, L. J. (1941). Arch. Surg., 42, 1065.

Vasko, J. R. (1946). J. Bone Jt Surg., 28, 638.

Weber, F. Parkes (1914). "Proc. XVIII Int. Congress of Medicine, London, 1913", Section 13, Pt 2, p. 179. Oxford University Press, London.

\section{Calcification vasculaire et articulaire hérédo-familiale}

\section{RÉSUMÉ}

Dans une famille de quatre enfants née de l'union de cousins germains, deux d'entre eux sont atteints de calcification des structures articulaires et artérielles d'un type rare, associée à la néoformation osseuse, juxtaarticulaire et périostique.
Les deux autres, ainsi que le fils et la fille de l'un des plus gravement atteints, semblent présenter une forme plus benigne de ce syndrome car chez eux l'atteinte ne porte que sur les vaisseaux sanguins.

Il s'agit ici probablement d'une forme hérédo-familiale rare et distincte de calcification dystrophique.

\section{Calcificación vascular $\mathbf{y}$ articular heredo-familiar}

\section{Sumario}

Dos de los cuatro hijos, frutos de la union de primos hermanos, presentan una calcificación de estructuras articulares y arteriales de un tipo raro, asociada con neoformación ósea, yuxta-articular y perióstea.

Los dos demás, así como un hijo y una hija de uno de los precitados parecen sufrir de una forma más benigna de este síndroma, que en ellos afecta sólo los vasos sanguíneos.

Se trata sin duda de una forma heredo-familiar, rara y distinta, de calcificación distrófica. 